\title{
RELATO DE CASO: VIVÊNCIA DA DISCIPLINA ESTÁGIO CURRICULAR SUPER VISIONADO NA UNIDADE DE SAÚDE DA FAMÍLIA.
}

\section{CASE REPORT: DISCIPLINE SUPERVISED INTERNSHIP EXPERIENCE IN FAMILY HEALTH UNIT.}

\author{
Edla Lobo Muniz \\ Universidade Federal da Bahia \\ edlamuniz@hotmail.com
}

\begin{abstract}
RESUMO
Com o que preconiza o Programa de Saúde da Família, a nova matriz curricular de enfermagem foi adaptada a fim de proporcionar a inserção do aluno o mais breve possível no contexto de saúde pública. O Estágio Curricular Supervisionado vem com o intuito de preparar os profissionais em formação para o campo de trabalho, visto que a atenção básica se tornou o local que mais os absorve. Este artigo foi realizado como relato de experiência após o período de vivência na Unidade de Saúde da Família Centro Social Urbano _ Solange Hortélio Franco na cidade de Vitória da Conquista (BA), com o objetivo de descrever as dificuldades e facilidades do que o estágio propôs ao aluno. Pode-se perceber que esta oportunidade permite que se desenvolva não somente o lado profissional, teórico-prático, mas também o lado pessoal.
\end{abstract}

Palavras-Chave: PSF; experiência; enfermagem; estágio; habilidade.

\begin{abstract}
With what advocates the Family Health Program, the new curriculum model for Nursing Program was adapted to provide the student insertion as soon as possible in public health context. The Supervised Internship comes intending to prepare professionals in training for labor camp, because primary care has become the place that absorbs them more. This article was realized as a case report after the experience period in the Urban Social Center _ Solange Hortélio Franco family health unit, in Vitória da Conquista city (Bahia), with the objective of describing difficulties and facilities that the internship proposed to the student. It can be noticed that this opportunity avoid developing not only the professional, theoretical and practical side, but also the personal side.
\end{abstract}

Keywords: PSF; experience; nursing; stage; ability. 


\title{
Introdução
}

Nas primeiras escolas de enfermagem a matriz curricular tinha, para a formação dos alunos, o foco curativista/hospitalocêntrico devido a um contexto histórico da área de saúde brasileira que subestimava a importância da saúde pública. Depois da criação do Sistema Único de Saúde (SUS) pela Constituição e sua promulgação com a lei 8.080/90, começou-se a pensar em uma formação profissional que atendesse a nova demanda pela saúde básica. Para que ocorresse tal adequação, com a Portaria n. 1721/94, a disciplina de Saúde Pública passou a ser obrigatória e os Estágios Supervisionados teriam também a inserção dos graduandos em enfermagem no campo da rede básica.

Estes entraram em contato com uma nova estratégia, o Programa de Saúde da Família (PSF), criado em 1994 e que tinha como objetivo ampliar o Programa de Agentes Comunitários em Saúde (PACS) de 1991 (VIANA; DAL POZ, 1998).

A implantação do PSF não significou a substituição por um novo serviço de saúde, mas a implementação daquele existente, modificando as práticas tradicionais centradas no modelo curativo para outro, preventivo e promotor de qualidade de vida na população (BRASIL, 2000).

A proposta do PSF é colocar a família como foco da atenção em saúde, ampliando o conceito de integralidade, vendo o usuário como um todo na sociedade e levando em conta o meio em que este se insere, suas condições sociais e psicológicas, muito além da divisão do indivíduo nas especializações.

Segundo o MS,

\begin{abstract}
"mais que uma delimitação geográfica, é nesse espaço que se constroem as relações intra e extra-familiares e onde se desenvolve a luta pela melhora das condições de vida - permitindo, ainda, uma compreensão ampliada do processo saúde/doença e, portanto, da necessidade de intervenções de maior impacto e significação social. As ações sobre esse espaço representam desafios a um olhar técnico e político mais ousado, que rompam os muros das unidades de saúde e se enraízem para o meio onde as pessoas vivem, trabalham e se relacionam" (BRASIL, 1997).
\end{abstract}

O Ministério da Saúde institui que cada Equipe de Saúde da Família, de maneira básica, seja composta por um enfermeiro, um auxiliar de enfermagem e um médico generalista, o que insere a enfermagem de maneira ativa no processo de prevenção e promoção à saúde. A formação da enfermagem com enfoque em saúde coletiva prepara estes para a inclusão no mercado de trabalho que, atualmente, absorve grande parte dos profissionais (MARQUES e SILVA, 2004). 
Observando a mudança no novo contexto de saúde brasileira e das novas necessidades das organizações de trabalho, o Ministério da Educação propôs uma adaptação da matriz curricular, assim instituindo em 7/11/2001 pelo Centro Nacional de Educação/Centro de Ensino Superior (CNE/CES) a resolução $\mathrm{n}^{\circ} 3$ que remodelou as Diretrizes Curriculares Nacionais do curso de graduação em Enfermagem.

Sendo assim,

\begin{abstract}
Art. $7^{\circ} \mathrm{Na}$ formação do Enfermeiro, além dos conteúdos teóricos e práticos desenvolvidos ao longo de sua formação, ficam os cursos obrigados a incluir no currículo o estágio supervisionado em hospitais gerais e especializados, ambulatórios, rede básica de serviços de saúde e comunidades nos dois últimos semestres do Curso de Graduação em Enfermagem.

Parágrafo único. Na elaboração da programação e no processo de supervisão do aluno, em estágio curricular supervisionado pelo professor, será assegurada efetiva participação dos enfermeiros do serviço de saúde onde se desenvolve o referido estágio. A carga horária mínima do estágio curricular supervisionado deverá totalizar $20 \%$ (vinte por cento) da carga horária total do Curso de Graduação em Enfermagem proposto, com base no Parecer/Resolução específico da Câmara de Educação Superior do Conselho Nacional de Educação.
\end{abstract}

O Estágio Supervisionado se propõe a inserir o graduando na realidade social local da saúde através da prática e adaptá-lo ao contexto do ambiente de trabalho. Assim, gradualmente, este entrará em contato com as atribuições dos profissionais de sua área e reiterará a importância da interdisciplinaridade para o cuidado dos usuários da rede. Por este motivo, tal artigo tem como objetivo relatar o período de 4 meses de vivência experimentada por estudantes de enfermagem do $8^{\circ}$ semestre desta disciplina da Universidade Federal da Bahia (UFBA) na cidade de Vitória da Conquista, bem como as considerações finais dos mesmos sobre os entraves e ganhos no processo de aprendizagem.

\title{
Metodologia
}

Este artigo se trata de um relato de caso proposto pelo Estágio Supervisionado que foi atribuído como disciplina conclusiva do curso de graduação em Enfermagem da Universidade Federal da Bahia (UFBA) e realizado na unidade de saúde Centro Social Urbano - Solange Hortélio Franco (CSU) na cidade de Vitória da Conquista (BA), no período de 8 de outubro de 2012 a 21 de fevereiro de 2013. 


\section{Discussão}

O período de Vivência do Estágio Supervisionado nos proporcionou experiência ímpar na formação como enfermeiros. O processo de inserção no trabalho da equipe se deu de maneira suave e gradativa, iniciando com o reconhecimento interno e externo da área para que fosse possível a observação do perfil sócio-demográfico em questão. A compreensão de uma equipe de saúde já desenvolvida, com problemas e atribuições reais na sociedade, ampliou nossa visão de integralidade na assistência à saúde, não somente observando o usuário como alguém passível de presença ou ausência de doença, mas também como ser humano participante de uma comunidade em seu aspecto psicológico, econômico e social.

De acordo com a Resolução do CNE/CES N 3, de 7 de novembro de 2001, os cursos de enfermagem devem estar aptos a formarem profissionais críticos, reflexivos e humanistas. Para isto propõe que, durante a prática de enfermagem, é necessário o aperfeiçoamento de seis habilidades básicas para o contato com o serviço de saúde, a saber:

Atenção à saúde

I - Atenção à saúde: os profissionais de saúde, dentro de seu âmbito profissional, devem estar aptos a desenvolver ações de prevenção, promoção, proteção e reabilitação da saúde, tanto em nível individual quanto coletivo. Cada profissional deve assegurar que sua prática seja realizada de forma integrada e contínua com as demais instâncias do sistema de saúde, sendo capaz de pensar criticamente, de analisar os problemas da sociedade e de procurar soluções para os mesmos. Os profissionais devem realizar seus serviços dentro dos mais altos padrões de qualidade e dos princípios da ética/bioética, tendo em conta que a responsabilidade da atenção à saúde não se encerra com o ato técnico, mas sim, com a resolução do problema de saúde, tanto em nível individual como coletivo. (BRASIL, 2001)

Neste sentido, nossas atividades tiveram enfoque na assistência à saúde com a inserção e desenvolvimento nos programas já existentes na Unidade, sendo estes: o programa de acompanhamento à gestante, puericultura, consulta de enfermagem ginecológica com coleta de citopatológico, planejamento familiar, controle de hipertensão e diabetes (HiperDia) e visitas domiciliares. Durante as atividades englobamos campanhas de nível nacional como o Outubro Rosa (26/10), voltado à 
saúde da mulher, em prol do combate ao câncer de mama e de colo de útero, Novembro Azul (01/12), com enfoque à saúde do homem na prevenção do câncer de próstata, Dia do Diabético (14/11), na promoção à detecção precoce e controle do Diabetes Melitus e Dia Mundial de Combate à Hanseníase (31/01) para a promoção do combate à Hanseníase.

Por meio destas ações foi possível ampliar habilidades práticas e teóricas adquiridas ao longo da graduação, não somente no âmbito científico, mas também na fomentação da identidade como futuras enfermeiras e no crescimento do relacionamento interpessoal, tanto no contato com o paciente quanto com a equipe.

Tais relações vivenciadas no estágio permitiram um gradativo aumento de confiança, proporcionando que a habilidade de tomada de decisões fosse exercitada em virtude da autonomia que nos foi oferecida. Tal fato vai ao encontro com o que propõe o Ministério da Educação, pois, no artigo segundo se expõe:

II - Tomada de decisões: o trabalho dos profissionais de saúde deve estar fundamentado na capacidade de tomar decisões visando o uso apropriado, eficácia e custo-efetividade, da força de trabalho, de medicamentos, de equipamentos, de procedimentos e de práticas. Para este fim, os mesmos devem possuir competências e habilidades para avaliar, sistematizar e decidir as condutas mais adequadas, baseadas em evidências científicas. (BRASIL, 2001)

Devido à liberdade concedida no desenvolvimento das práticas de Estágio Supervisionado, muito maior do que em qualquer outra disciplina do curso, as tomadas de decisões puderam ser feitas de maneira integral. Tal empoderamento nos foi concedido de maneira gradual por meio do conhecimento adquirido e do trabalho psicológico dos docentes no decorrer da graduação.

Segundo Marquis e Huston (2010), "Decidir, assim, é a atividade mais inata de um líder e o elemento central de uma administração", o que faz com que a tomada de decisões seja um dos elementos mais cruciais a serem desenvolvidos durante o estágio, visto que a liderança é uma realidade elementar na formação de enfermagem. Deste modo, foi possível, dentro das atribuições do enfermeiro, atender as necessidades e servir à comunidade tendo a visão dos profissionais. Tal fato nos tornará mais preparados para a realidade do mercado de trabalho na área de saúde logo após a graduação. 
Partindo-se do conceito de que a tomada de decisão só se torna possível quando exercitada uma comunicação pertinente com os membros da equipe e a comunidade, esta se torna uma importante ferramenta para que o enfermeiro possa exercer seu papel de modo mais completo. Sabendo disto a diretriz curricular expõe,

III - Comunicação: os profissionais de saúde devem ser acessíveis e devem
manter a confidencialidade das informações a eles confiadas, na interação
com outros profissionais de saúde e o público em geral. A comunicação
envolve comunicação verbal, não-verbal e habilidades de escrita e leitura; o
domínio de, pelo menos, uma língua estrangeira e de tecnologias de
comunicação e informação. (BRASIL, 2001)

Esta característica é de suma importância na formação do enfermeiro, pois faz com que este desenvolva seu papel de cuidador e líder da equipe. Através disto, nos foi possível articular, de modo bastante saudável, o gerenciamento pessoal, de recursos e de atividades. Assim, surgiram oportunidades de desenvolver outras funções que, a princípio, estariam restritas à equipe, como capacitações e reuniões.

O Estágio Supervisionado mostra que a comunicação não é algo intrínseco, podendo ser trabalhado durante o período de vivência. Apesar de não termos encontrado dificuldades importantes ou resistência da equipe, percebemos que houve um aperfeiçoamento significativo desta capacidade.

A comunicação deve ser exercitada nos graduandos de enfermagem, pois esta é a forma com que este exercerá sua influência como um líder. Segundo Chiavenato, "os líderes eficazes são hábeis em comunicar, seja na forma escrita, oral ou não-verbal". Deste modo, de acordo com a diretriz,

IV - Liderança: no trabalho em equipe multiprofissional, os profissionais de saúde deverão estar aptos a assumir posições de liderança, sempre tendo em vista o bem-estar da comunidade. A liderança envolve compromisso, responsabilidade, empatia, habilidade para tomada de decisões, comunicação e gerenciamento de forma efetiva e eficaz.

Foi possível observar que o trabalho de liderança da enfermagem influencia a unidade como um todo, fazendo com que todos os serviços, sejam eles gerenciais ou assistenciais, fluam de modo mais coeso com a presença do enfermeiro, mesmo que a forma de liderança contenha características pessoais de cada líder.

Durante o processo, nos foi mostrada a dimensão da influência do enfermeiro sobre os profissionais da equipe e toda a dinâmica da unidade de saúde. É imperioso 
salientar que, na atenção básica, a enfermagem não tem papel coadjuvante na construção da saúde pública. Até então, as demais atividades práticas da graduação mostravam um trabalho fragmentado, portanto não nos era possível analisar a importância de ser um bom líder, o que foi despertado durante esta disciplina.

A liderança é muito importante quando acompanhada da gerência, pois de acordo com Hunter "gerenciam-se coisas, lideram-se pessoas". O ideal seria que ambas as habilidades fossem exercidas de forma conjunta, uma vez que "todo administrador ou gerente precisa ser um líder, embora nem todo líder seja um administrador ou gerente”. (CHIAVENATO, 2010a)

Segundo a nova diretriz,

\begin{abstract}
V - Administração e gerenciamento: os profissionais devem estar aptos a tomar iniciativas, fazer o gerenciamento e administração tanto da força de trabalho quanto dos recursos físicos e materiais e de informação, da mesma forma que devem estar aptos a serem empreendedores, gestores, empregadores ou lideranças na equipe de saúde. (BRASIL, 2001)
\end{abstract}

Pode-se perceber que o gerenciamento e enfermagem andam interligados. $\mathrm{O}$ trabalho do enfermeiro é dividido entre a administração de questões de gerenciamento de pessoas, de materiais, preenchimento de fichas para alimentar o sistema e o atendimento assistencial, o que, muitas vezes, demanda um tempo que poderia ser aproveitado em outras atividades que potencializassem o trabalho e o tornasse mais efetivo e com maior qualidade.

No percurso do estágio foi possível realizar algumas atividades gerenciais de forma mais tranqüila do que a real atribuição do enfermeiro. O que se percebe é que SUS propõe a humanização do atendimento, mas muitas vezes não leva em consideração que o profissional se desencontra nas questões gerenciais, principalmente no que tange a produtividade, assim mecanizando a mão de obra em um formato Taylorista.

No mercado atual, para que esta seja menos mecanizada, o profissional deve estar sempre em busca de conhecimento. O profissional de saúde necessita também gerenciar a si mesmo na busca de aprendizado contínuo, inclusive com novas habilidades. (CHIAVENATO, 2010b) Visando preparar o graduando em enfermagem até mesmo neste aspecto, o CNE/CES propõe, 
VI - Educação permanente: os profissionais devem ser capazes de aprender continuamente, tanto na sua formação, quanto na sua prática. Desta forma, os profissionais de saúde devem aprender a aprender e ter responsabilidade e compromisso com a sua educação e o treinamento/estágios das futuras gerações de profissionais, mas proporcionando condições para que haja benefício mútuo entre os futuros profissionais e os profissionais dos serviços, inclusive, estimulando e desenvolvendo a mobilidade acadêmico/profissional, a formação e a cooperação por meio de redes nacionais e internacionais. (BRASIL, 2001)

As atividades de educação permanente são amplamente desenvolvidas na unidade, desde grupos de educação com a comunidade, salas de espera e aperfeiçoamento dos profissionais. Semanalmente foi possível a realização de atividades educativas em todos os âmbitos do atendimento ao público (grupos de gestantes, hipertensos e diabéticos, planejamento familiar, aconselhamento sobre DST), além de desenvolvimento de capacitação com os profissionais da unidade e atividade extra-muros com adolescentes em colégio público.

Tal fato é ponto positivo para a saúde pública de modo geral, pois, além de estreitar o vínculo dos trabalhadores com a comunidade, ainda propõe constante aperfeiçoamento de conhecimentos e técnicas a todos.

\section{Considerações finais}

O conhecimento não é algo fixo e pré-moldado na vivência. O dinamismo do processo faz com que o planejamento nem sempre seja compreendido de forma íntegra. Tal variação torna possível a adaptação às situações que surgem, e é este aprendizado o mais significativo e singular oferecido no período da disciplina. Nesta caminhada foi possível o crescimento intelectual e pessoal imprescindível para a vida após o momento acadêmico. Tal fato só foi possível graças à colaboração do preceptor e dos profissionais da unidade que permitiram que este estágio fosse o mais proveitoso possível.

Concordamos que a atenção básica passa aos poucos a ser elucidada neste período, mesmo que alguns aspectos, como o fluxo do trabalho burocrático (marcações de exames, registros de produtividade do serviço, fichas de notificação, dentre outras) não tenha sido totalmente clarificado, o que possibilitaria a consolidação do entendimento dos problemas da rede SUS. 
A disciplina de Estágio Supervisionado propôs um elo mais forte entre nós, acadêmicos, e a sociedade, permitindo a experimentação do trabalho como enfermeiros e reafirmando a importância dos laços na construção do conhecimento em saúde.

\section{Referências}

BRASIL. Lei $\mathrm{N}^{\mathrm{o}} 7.498$, de 25 de junho de 1986. Dispõe sobre o exercício da enfermagem e dá outras providências. Diário Oficial da República Federativa do Brasil, 26 Jun 1986.

BRASIL. Lei no. 8080 de 19 de setembro de 1990. Dispõe sobre as condições para a promoção, proteção e recuperação da saúde, a organização e o funcionamento dos serviços correspondentes e dá outras providências. Diário Oficial da União, Poder Executivo; 1990 Set. 20.

BRASIL. Ministério da Educação e do Desporto. Portaria No 172, de 15 de dezembro de 1994. Dispõe sobre a formação do enfermeiro de graduação. Diário Oficial da República Federativa do Brasil, 16 Dez 1994.

BRASIL. Resolução CNE/CES Nº 3, de 7 de novembro de 2001. Diário Oficial da União, Brasília, DF, 9 de Novembro de 2001. Seção 1, p. 37.

BRASIL. Saúde da Família: Uma estratégia de reorientação do modelo assistencial. Ministério da Saúde, 1997. 36p.

BRASIL. Secretaria de Políticas de Saúde. Departamento de Atenção Básica.Programa de Saúde da Família: informe técnico institucional. Ver Saúde Pública 2000;34(3):3169.

CHIAVENATO, Idalberto. Liderança, poder e política. Comportamento Organizacional Rio de Janeiro Elsevier, 2010. p.350-355 
Ensino, Saúde e Ambiente - V6 (3), pp. 73-82, dez. 2013

COSTA, Lauriana M; GERMANO, Raimunda M. Estágio curricular supervisionado na Graduação em Enfermagem: revisitando a história. Revista Brasileira de Enfermagem. Brasília. P.706-10,2007.

HUNTER, James. O monge e o executivo. Rio de Janeiro. Sextante. 2004.

MARQUES, Dalvani; Silva, Eliete M. A Enfermagem e o Programa Saúde da Família: uma parceria de sucesso? Rev Bras Enferm, Brasília (DF) 545-50, 2004.

MARQUIS,L. Bessie; HUSTON, J. Carol. Integração e administração: uma nova abordagem. Administração e liderança em enfermagem. $4^{\mathrm{a}}$ ed. Porto Alegre: Artmed, 2005 .

VIANA, Ana Luiza D; POZ, Mario Roberto D. A Reforma do Sistema de Saúde no Brasil e o Programa de Saúde da Família. Rev. Saúde Coletiva, Rio de Janeiro, 15(Suplemento): 225- 264, 2005. 